\title{
Commentary
}

\section{Have Sex or Not? Lessons from Bacteria}

\author{
T. Lodé \\ UMR CNRS 6552 ETHOS, Université de Rennes 1, Campus de Beaulieu, Rennes, France
}

\section{Key Words}

Asexual reproduction $\cdot$ Eukaryotes $\cdot$ Libertine bubble

theory $\cdot$ Meiosis $\cdot$ Sex origin

\begin{abstract}
Sex is one of the greatest puzzles in evolutionary biology. A true meiotic process occurs only in eukaryotes, while in bacteria, gene transcription is fragmentary, so asexual reproduction in this case really means clonal reproduction. Sex could stem from a signal that leads to increased reproductive output of all interacting individuals and could be understood as a secondary consequence of primitive metabolic reactions. Meiotic sex evolved in proto-eukaryotes to solve a problem that bacteria did not have, namely a large amount of DNA material, occurring in an archaic step of proto-cell formation and genetic exchanges. Rather than providing selective advantages through reproduction, sex could be thought of as a series of separate events which combines step-by-step some very weak benefits of recombination, meiosis, gametogenesis and syngamy.
\end{abstract}

Copyright $\odot 2012$ S. Karger AG, Basel
(C) 2012 S. Karger AG, Basel

1661-5425/12/0066-0325\$38.00/0

Fax +4161306 1234

E-Mail karger@karger.ch

www.karger.com
Accessible online at: www.karger.com/sxd
Why sex is so pervasive in eukaryotes is one of the major unresolved issues in evolutionary biology. Sexual species are expected to suffer from the 2-fold cost of sex [Doncaster et al., 2000], and sexual reproduction has led to the evolution of 2 sexes with opposing reproductive interests [Arnqvist and Rowe, 2005; Gavrilets and Hayashi, 2005]. It has been argued that, by combining and removing deleterious alleles, sex favors adaptation [Kondrashov, 1994; Otto and Gerstein, 2006; de Visser and Elena, 2007]. However, it could be countered that diploidy also allows recessive deleterious mutations to accumulate in the genome because alleles are masked in the heterozygous state.

The recombination of genes is indeed shared in both eukaryotic and some prokaryotic phyla, suggesting both an ancient origin and a common function [Penny, 1985]. However, sexual reproduction is not characterized only by recombination and sex should be defined as a process which combines recombination, meiosis, gametogenesis and syngamy. Although some fungi seem to show multiple mating types, the definition of sex centers on the nature of a sexual cell being produced [Hurst, 1996], so that it could be reasoned that there are only 2 sexes: males with motile sperm and females with larger eggs. Further, it may be thought that isogamy had been the ancestral state [Dunthorn and Katz, 2010]. 


\section{Recombination in Bacteria}

Bacteria can acquire genes by taking up some plasmid genes from a bacterial donor (bacterial competence), especially from dead bacterial cells, resulting in a gene conversion event and leading to permanent changes in their phenotype [Bendich and Drlica, 2000]. Bacterial conjugation is often regarded as the equivalent of sex, but in a rigorous analysis of gene transfer mechanisms, Redfield [2001] showed that bacterial rec genes should only be considered as a DNA repair mechanism. Indeed, bacterial rec genes are only implicated in some forms of homologous recombination and a critical analysis of the genes responsible for the conjugation or gene transfer processes suggests that they did not evolve for sexual reproduction [Redfield, 2001]. The donor carries a replicon that can replicate autonomously in the cell. So, in bacteria, gene transcription is fragmentary although Rec proteins are implicated in bacterial DNA repair mechanisms. The length of the DNA fragment randomly transmitted during bacterial 'conjugation' strictly depends on the duration of contact, and the transfer is only partial from a donor to a recipient cell.

Moreover, in most bacterial gene transfer mechanisms (conjugation, transduction, transformation), there is no recombination of the main chromosome, so it could be asserted that 'bacteria lack genes for sex' [Redfield, 2009]. Genetic exchanges occur as unselected side effects of processes that evolved for more immediate functions [Redfield, 2009]. Thus, most models do not take into account why some organisms, such as bacteria, are able to spread and to survive severe conditions without sexual reproduction. Conversely, and because of their comparable ecology, the reason why protists need sex and genetic exchanges (true conjugation) should be understood. Furthermore, while current models can explain well how some events of recombination can be favored over the total lack of sex, the fact that some lines have been moving towards an obligate sexual reproduction remains difficult to understand.

\section{Confusion in Asexual Reproduction}

Most descriptions of asexual reproduction are particularly confused. Some worm species reproducing asexually by fission (scissiparity) have revealed hybrid origins, and transformation into a pelagic sexual morph (epigamy or epitoky) was their ancestral reproductive state [Nygren and Sundberg, 2003; Lunt, 2008]. Parthenogenetic species, such as Cnemidophorus lizards [Parker and Selander, 1976;
Crews and Fitzgerald, 1980], hybridogenetic waterfrogs [Pagano et al., 2003] and Poeciliopsis fishes [Schartl et al., 1995] are believed to use clonal or hemiclonal asexual reproduction, but these unisexual populations generally originated from hybridization with sexual species and exhibit numerous traits shared by their gonochoristic species (i.e. separate sexes in distinct individuals). It could be argued that these populations have lost sex by adopting a form of endomitosis reproduction, often with a normal meiosis preceded by a replication. In numerous plants, apomixis occurs with a meiosis in which one division is suppressed. Oribatid mites can show a reversal from 'obligate' asexual forms to sexual forms [Domes et al., 2007], but sexuality might have been lost repeatedly [Goldberg and Igic, 2008]. In some vertebrates, asexual reproduction could be linked to hybridization [Crews et al., 1986]. Analyses of bdelloid rotifer lineages suggest that sex has been repeatedly lost during their evolutionary history [MarkWelch and Meselson, 2000]. Similarly, a sexual stage was evidenced in the theoretically 'obligatory' asexual fungus Aspergillus fumigatus [Dyer and Paoletti, 2005]. Finally, numerous species depend on environmental triggers to determine sex and, in some fishes, this process persists throughout life. Indeed, although recombination provides advantages, some species from sexual lineages could have lost sexual reproduction especially when a genome conflict occurs. Thus, it could be thought that so-called 'asexual' eukaryotic organisms have shown a decline in sexual fertility or have lost sex during their evolutionary history, although they have sexual ancestry.

By contrast, bacteria show neither meiosis nor features required for a true mitotic process, so the absence of sex in bacteria really means clonal reproduction [Bendich and Drlica, 2000; Lewis 2001]. McDaniel et al. [2010], however, found that high genetic transfer in marine bacteria resulted from gene transfer agents, which demonstrated the widespread capability of variance and adaptation in bacteria without sexual practices. Similarly, numerous clonal genomes have revealed great adaptive potential [Loxdale and Lushai, 2003].

Consequently, it could be speculated that meiotic sex evolved because primitive eukaryotes had to resolve a problem that bacteria do not have.

\section{Meiotic Sex}

The oldest eukaryotes appeared more than 3 billion years ago [Javaux et al., 2010], so it is plausible that protoeukaryotes diverged from prokaryotes very early in the 
evolutionary history [Egel, 2012]. Genetic exchanges appear to be a very archaic process, and sex may originate from horizontal gene transfer occurring in primitive steps of proto-cell development [Lodé, 2011]. Considering the large differences between bacteria and eukaryotes, sexual meiosis can be explained as a secondary consequence of the transfer of large amounts of genetic material [Lodé 2012a, b]. Meiosis originated from a primitive DNA repair mechanism and may occur because DNA can prevent degradation only by recombination [Lichten, 2001]. Physicochemical constraints governing cell structure should be an essential aspect of cell origin.

Sometimes, several copies of the bacterial chromosome could be found in bacteria, but the bacterial cell division occurs soon after replication of its DNA (or after the transfer of a new DNA fragment) suggesting that the quantity of genetic material affects the physicochemical cell integrity. While bacteria generally carry genetic material in the form of a unique circular chromosome and are usually haploid, the size of eukaryotic genomes is very much larger, and most species are diploid or polyploid. Rather than a self-replication of a 'naked-gene', lipid membrane-bound proto-cell 'bubbles' provide a favorable environment for prebiotic components [Szostak et al., 2001] and the emergence of genetic sexual replication [Lodé, 2011]. It can be suggested that the difference of cell proto-membranes built the first major evolutionary bifurcation between bacteria and eukaryotes. The protomembrane should have kept a partial permeability, whereas the peptidoglycan cell wall of bacteria served as protection against severe primitive environmental conditions, maybe because the proto-eukaryotes were housed in hollows of the primitive substrate. Some rare bacteria are known to possess polyploid genomes correlated with the cell size but, although these bacteria may have acquired some of the advantages of eukaryotes, the abundance of genome copies results in unstable genetic features [Mendell et al., 2008].

Anyway, sexual recombination can be portrayed as a secondary consequence of primitive metabolic reactions. Eukaryotic microorganisms may rely on aggregative behavior to reproduce since sexual exchanges are only induced by density-dependent stressful conditions, such as overcrowding [Bell, 1988; Bernstein and Bernstein, 2010]. Indeed, sex could stem from a signal that leads to increased reproductive output of all interacting individuals and evolved as a more and more efficient specialized interaction. The fact that numerous patterns of facilitation of reproduction can be found in sexual and asexual eukaryotes suggests it to be an ancestral trait [Crews, 1982], and Crews
[2012] argued that sexual 'behavior', i.e. facilitation of reproduction, could have preceded sexual reproduction.

The simple contact among the pre-biotic bubbles could, through primitive food or parasitic reactions, have acted as facilitation for promoting the transfer of genetic material from one proto-cell to another, leading to an 'overload' of DNA at the origin of diploidy. The redistribution of the excess of genetic material from a proto-cell merger would be a driving force in the origin of sex. Diploidy may have resulted from an excess of DNA in the form of linear chromosomes, but then could have provided redundancy and facilities for gene repair. The evolution of nuclear compartment in proto-eukaryotic cells could have resulted from physicochemical forces [Kurland et al., 2006; Lodé, 2012a]. In the evolution of meiosis from mitosis, crossing over appeared before the reductional cell division [Wilkins and Holliday, 2009]. In fact, transferred DNA fragments can avoid degradation only by recombining with the genetic material of the host [Lichten, 2001] and the DNA is deactivated by being enclosed in the lamina network of the nuclear membrane [Dahl et al., 2004], decoupling gene translation from transcription. Histones form the nucleosome as a nonlinear structure (chromatin) stabilizing the genetic material. Proto-eukaryotes may have solved the problem of 'excess' of diploid DNA through a reductional process nowadays known as meiosis producing haploid gametes. The fact that genes involved in meiotic mechanisms are conserved across eukaryotic phyla suggests a common origin of eukaryotes [Solari, 2002].

As a physical process of the exchange of DNA, recombination may also be a blind way for a self-promoting element to spread [Lesbarrères, 2011; Lodé, 2011]. The hypothesis that meiosis favors intergenic recombination is not discarded, but I argue that this possible benefit provided the primary selective pressure initiating sex. Then, eukaryotes could link gene exchange and reproduction through the fusion of 2 gametes (syngamy). While bacterial reproduction did not require any change in ploidy, sexual reproduction is characterized by an alternation of diploid and haploid phases. By providing a means of organized genetic reduction, meiosis could have facilitated the origin of sexual reproduction in eukaryotes.

\section{Conclusion}

Thus, sex should be defined as a process which combines step-by-step recombination, meiosis, gametogenesis and syngamy. Thus, sex should not be considered to 
be a unitary phenomenon, but rather a series of separate events. Genetic exchanges and recombination among proto-eukaryotes would be mutually advantageous, increasing the potential of adaptive evolution and favoring sex in their evolution. This evolutionary scenario seems reasonable because genetic exchanges renovate the set of proteins involved in metabolic reactions and may result in adaptations for dealing with stress, especially in overcrowding conditions. A similar phenomenon occurs in sexual conjugation of protists under density-dependent conditions [Bernstein and Bernstein, 2010]. Then, gametes developed in specialized containers of DNA able to be dispersed and specific sexual traits evolved to attract congeners of the opposite sex, and thereby to favor sexual reproduction. It has also been suggested that eukaryotic lineages evolved from ancestors that could adopt both male and female roles [Crews, 2012]. Finally, it may be predicted that the cost of sex may vary across evolutionary lineages with dimorphism and anisogamy.

\section{Acknowledgements}

I would like to thank David Crews for helpful comments on the first draft of my study.

\section{References}

Arnqvist G, Rowe L: Sexual Conflict (Princeton $>$ Egel R: Primal eukaryogenesis: on the commuUniversity Press, Princeton, 2005).

Bell G: Sex and Death in Protozoa (Cambridge University Press, Cambridge, 1998).

Bendich AJ, Drlica K: Prokaryotic and eukaryotic chromosomes, what's the difference? BioEssays 22:481-486 (2000).

Bernstein H, Bernstein C: Evolutionary origin of recombination during meiosis. BioScience 60:498-505 (2010).

Crews D: On the origin of sexual behavior. Psychoneuroendocrinology 7:259-270 (1982).

Crews D: The (bi)sexual brain. EMBO Rep (in press, 2012).

Crews D, Fitzgerald KT: Sexual behavior in parthenogenetic lizards (Cnemidophorus). Proc Natl Acad Sci USA 77:499-502 (1980).

-Crews D, Grassman M, Lindzey J: Behavioral facilitation of reproduction in sexual and unisexual whiptail lizards. Proc Natl Acad Sci USA 83:9547-9550 (1986).

-Dahl KN, Kahn SM, Wilson KL, Discher DE: The nuclear envelope lamina network has elasticity and a compressibility limit suggestive of a molecular shock absorber. J Cell Sci 117:4779-4786 (2004).

de Visser JA, Elena SF: The evolution of sex: empirical insights into the roles of epistasis and drift. Nat Rev Genet 8:139-149 (2007).

Domes K, Norton RA, Maraun M, Scheu S: Revolution of sexuality breaks Dollo's law. Proc Natl Acad Sci USA 104:7139-7144 (2007).

Doncaster CP, Pound GE, Cox SJ: The ecological cost of sex. Nature 404:281-285 (2000).

-Dunthorn M, Katz LA: Secretive ciliates and putative asexuality in microbial eukaryotes. Trends Microbiol 18:183-188 (2010).

Dyer PS, Paoletti M: Reproduction in Aspergillus fumigatus, sexuality in a supposedly asexual species? Med Mycol 43(suppl 1):S7-S14 (2005). nal nature of precellular states, ancestral to modern life. Life 2:170-212 (2012).

Gavrilets S, Hayashi TI: Sexual conflict and speciation. Evol Ecol 19:167-198 (2005).

Goldberg EE, Igic B: On phylogenetic tests of ir reversible evolution. Evolution 62:2727-2741 (2008).

Hurst LD: Why are there only two sexes? Proc R N Soc Lond B Biol Sci 263:415-422 (1996).

-Javaux EJ, Marshall CP, Bekker A: Organicwalled microfossils in 3.2 billion-year-old shallow-marine siliciclastic deposits. Nature 463:934-938 (2010).

Kondrashov AS: Sex and deleterious mutations. Nature 369:99-100 (1994).

Kurland CG, Collins LJ, Penny D: Genomics and the irreducible nature of eukaryote cells. Science 312:1011-1014 (2006).

Lesbarrères D: Sex or no sex, reproduction is not the question. BioEssays 33:818 (2011).

Lewis PJ: Bacterial chromosome segregation. Microbiology 14:519-526 (2001).

Lichten M: Meiotic recombination: breaking the genome to save it. Curr Biol 11:253-256 (2001).

Lodé T: Sex is not a solution for reproduction: the libertine bubble theory. BioEssays 33:419422 (2011)

Lodé T: For quite a few chromosomes more: the origin of eukaryotes. J Mol Biol (in press 2012a).

Lodé T: Sex and the origin of genetic exchanges. Trends Biol Evol 4:e1 (2012b)

Loxdale HD, Lushai G: Rapid changes in clonal lines: the death of a 'sacred cow'. Biol J Linn Soc 79:3-16 (2003).

Lunt DH: Genetic tests of ancient asexuality in root knot nematodes reveal recent hybrid origins. BMC Evol Biol 8:194 (2008).

Mark-Welch D, Meselson M: Evidence for the evolution of bdelloid rotifers without sexual reproduction or genetic exchange. Science 288:1211-1215 (2000).
McDaniel LD, Young E, Delaney J, Ruhnau F, Ritchie KB, Paul JH: High frequency of horizontal gene transfer in the oceans. Science 330:50 (2010).

Mendell JE, Clements KD, Choat JH, Angert ER: Extreme polyploidy in a large bacterium. Proc Natl Acad Sci USA 105:6730-6734 (2008).

Nygren A, Sundberg P: Phylogeny and evolution of reproductive modes in Autolytinae (Syllidae, Annelida). Mol Phyl Evol 29:235-249 (2003).

Otto SP, Gerstein A: Why have sex? The population genetics of sex and recombination. Biochem Soc Trans 34:519-522 (2006).

Pagano A, Dubois A, Lesbarrères D, Lodé T: Frog alien species, a way for genetic invasion? CR Biol 326:85-92 (2003).

Parker ED Jr, Selander RK: The organization of genetic diversity in the parthenogenetic lizard Cnemidophorus tesselatus. Genetics 84: 791-805 (1976).

Penny D: The evolution of meiosis and sexual reproduction. Biol J Linn Soc 25:209-220 (1985).

Redfield RJ: Do bacteria have sex? Nat Rev Gen 2:634-639 (2001)

Redfield RJ: Looking to bacteria for clues. Science 325:946 (2009).

Schartl M, Wilde B, Schlupp I, Parzefall J: Evolutionary origin of a parthenoform, the Amazon molly Poecilia formosa, on the basis of a molecular genealogy. Evolution 49:827835 (1995).

Solari AJ: Primitive forms of meiosis: the possible evolution of meiosis. Biocell 26:1-13 (2002)

-Szostak JW, Bartel DP, Luisi PL: Synthesizing life. Nature 409:387-390 (2001).

-Wilkins AS, Holliday R: The evolution of meiosis from mitosis. Genetics 181:3-12 (2009). 